\title{
Erratum to: Gestural Representation of Emotions: A Comparative Study on Chilean and American Women
}

\author{
Paula Muñoz ${ }^{1} \cdot$ Chamarrita Farkas $^{1}$ - Claire D. Vallotton ${ }^{2}$
}

Published online: 4 July 2017

(C) Springer Science+Business Media, LLC 2017

\section{Erratum to: J Child Fam Stud (2017) DOI 10.1007/s10826-017-0724-6}

The authors have informed the Journal of Child and Family Studies that an author, Claire D. Vallotton, was inadvertently omitted from the first published version of their manuscript. The initial authorship list read as follows:

Paula Muñoz, Chamarrita Farkas

The revised authorship has been updated to the following list:
Paula Muñoz, Chamarrita Farkas, Claire D. Vallotton While Dr. Vallotton was omitted from the first published version of this manuscript, the revised authorship list has since been corrected online.

The information for contact of Dr. Vallotton is:

Michigan State University, East Lansing, MI, USA

mail: vallotto@msu.edu

The online version of the original article can be found at doi:10.1007/ s10826-017-0724-6.

Paula Muñoz

pcmunoz5@uc.cl

1 Pontificia Universidad Católica de Chile, Santiago, Región Metropolitana, Chile

2 Michigan State University, East Lansing, MI, USA 